\title{
Fibronectin Is More Active than Fibrin or Fibrinogen in Promoting Staphylococcus aureus Adherence to Inserted Intravascular Catheters
}

\author{
Pierre Vaudaux, Didier Pittet, André Haeberli, \\ Peter G. Lerch, Jean-Jacques Morgenthaler, \\ Richard A. Proctor, Francis A. Waldvogel, \\ and Daniel P. Lew
}

\author{
Division of Infectious Diseases, University Hospital, Geneva, and \\ Thrombosis Research Laboratory, University Hospital and Central \\ Laboratory, Blood Transfusion Service Swiss Red Cross. Bern, \\ Switzerland; Department of Medical Microbiology and Immunology. \\ University of Wisconsin, Madison
}

To further define the role of fibrin(ogen) and fibronectin in Staphylococcus aureus adherence to central venous catheters, the amount, chemical integrity, and biologic activity of these proteins adsorbed on lines inserted in hospitalized patients were prospectively studied. Polyurethane cannulas promoted a significantly lower adherence of $S$. aureus than polyvinyl chloride $(P<.01)$ or Hickman $(P<.001)$ cannulas and contained the lowest amount of immunologically assayed fibronectin but not of fibrin(ogen). Fibrinogen showed an extensive loss of adherence-promoting activity on inserted cannulas, which was related to its proteolytic breakdown, as detected by SDS-PAGE and immunoblots-with antifibrinogen antibodies and confirmed by in vitro studies with purified protein fragments. In contrast, either intact or fragmented fibronectin, although present in much lower amounts than fibrin(ogen), could actively promote $S$. aureus adherence onto intravenous catheters.

Microbial colonization of intravascular devices is an important source of nosocomial infection and sepsis [1,2]. Such device-related infections are frequently due to staphylococci and represent a major risk to the patients receiving intravenous (iv) therapy $[1,2]$. Several factors may explain the frequent colonization of iv devices by Staphylococcus aureus, Staphylococcus epidermidis, or other species of coagulase-negative staphylococci: First, the presence of a transcutaneous cannula wound allowing skin microorganisms to migrate across the skin barrier [1,2]; second, the microbial production of mucoid exopolymeric substances enhancing the stickiness of colonizing organisms [3-6]; and third, the presence of plasma proteins adsorbed on iv devices, which might selectively promote staphylococcal attachment to their surfaces [7-10].

We have reported that plasma proteins deposited on various categories of iv catheters removed from patients played a significant role in staphylococcal adherence [11]. Clinical isolates of $S$. aureus were more strongly promoted for adherence by cannula-adsorbed plasma proteins than clinical isolates of $S$. epidermidis [11]. This observation was explained in part by the more frequent occurrence of clinical $[8,12,13]$ and laboratory $[14-23]$ isolates of $S$. aureus than

Received 19 May 1992; revised 8 September 1992.

Presented in part: 30 th Interscience Conference on Antimicrobial Agents and Chemotherapy Atlanta, October 1990, (abstract 25).

Grant support: Swiss National Research Foundation (32.30161.90, 31.26500.89): National Institutes of Health (AI-16881).

Reprints or correspondence: Dr. Pierre Vaudaux, Division of Infectious Diseases, University Hospital, 1211 Geneva 14, Switzerland.

The Journal of Infectious Diseases 1993;167:633-41 (C) 1993 by The University of Chicago. All rights reserved. 0022-1899/93/6703-0017\$01.00 of $S$. epidermidis on surface determinants recognizing some major plasma or matrix proteins, such as fibronectin $[8,10$ 12,14-18], fibrinogen $[9,16,19-21]$, collagen [13, 17], laminin $[8,17,22]$, or vitronectin [23]. Each of these individual proteins is known to promote staphylococcal adherence when adsorbed in vitro on polymeric surfaces [8-10]. In our in vivo study, we also found that on cannulas inserted in patients, most of the adherence-promoting activity was mediated via surface-bound fibronectin and fibrinogen or fibrin [11]. However, the respective roles of each of these protein components in staphylococcal adherence could not be precisely evaluated [11].

The objectives of this study were to quantify the respective content of surface-bound fibronectin versus fibrinogen/ fibrin on inserted catheters and to define the role played by each of these proteins in the bacterial attachment process in vivo.

\section{Materials and Methods}

Collection of catheters. iv catheters from adult inpatients attending the Clinique Médicale Thérapeutique at Geneva University Hospital were consecutively removed for a 3-month period by a team of 2 trained nurses. We followed a previously described [11] protocol to collect clinical and laboratory data from each patient, except that only central and peripherally inserted central venous catheters were evaluated. A total of 65 central catheters inserted for an average of 9-11 days was collected. Inserted cannulas were 14 polyvinyl chloride (PVC) long lines (14-gauge Drum-Cartridge [Abbott, Sligo, Ireland] and 16gauge Intracath [Deseret, Sandy, UT]) and 51 16-gauge polyurethane (PUR) catheters of three different types. Twenty cannulas were Vialon (PUR-V; Deseret), 18 were Cavafix (PUR-C, Certo; B. Braun Melsungen Neuhausen, Germany), and 13 were 
Seldiflex (PUR-S; Plastimed, Saint-Leu, France). In addition, 15 previously inserted Hickman 9.6-French single lumen cannulas (Evermed, Cranston, RI) were collected from outpatients of the Oncology Unit of our hospital. There was no significant difference between PVC and PUR cannulas in the average duration of insertion. Similar proportions of iv catheters have been used for administering antimicrobial therapy, blood products, anticoagulants, or total parenteral nutrition in PVC and PUR cannula groups. The major reason for catheter removal was the end of iv therapy. When catheter-associated infection was suspected, semiquantitative cultures were done as described by Maki [2]; only one of these catheters showed significant tip colonization ( $>15 \mathrm{cfu}$ ), and no patient in this series had device-related bacteremia.

To quantify the volume of residual blood still associated with inserted cannulas after the rinsing procedure, done as previously described [11], we assayed the activity of endogenous peroxidase as a marker of contaminating red blood cells. Segments (1 $\mathrm{cm}$ long) of inserted cannulas were incubated for $15 \mathrm{~min}$ at $37^{\circ} \mathrm{C}$ with $0.01 \% \mathrm{H}_{2} \mathrm{O}_{2}$ and the chromogen 1,2-phenylenediamine dihydrochloride (OPD; Dakopatts, Glostrup, Denmark) according to the manufacturer's instructions. The content of endogenous peroxidase assayed by optical density readings at $492 \mathrm{~mm}$ in standard volumes of serially diluted whole blood incubated in parallel was used to estimate the volume of residual blood still associated with segments of previously inserted cannulas. A minimal amount $\left(5 \times 10^{-6} \mathrm{~mL}\right)$ of whole blood was detected by the colorimetric assay, which was linear up to $10^{-4}$ $\mathrm{mL}$. A cutoff point of $0.3 A_{492}$ was selected to differentiate between cannulas contaminated with more or less than $2 \times 10^{-5}$ $\mathrm{mL}$ of blood per $1-\mathrm{cm}$-long cannula segment, which would represent maximal carryover of 6 and $60 \mathrm{ng}$ of plasma fibronectin and fibrin(ogen), respectively.

Chemicals and materials. $\quad\left[{ }^{3} \mathrm{H}\right]$ thymidine, purified human fibronectin, serum albumin, and fibrinogen were obtained as previously described $[8,11]$.

Preparation of purified fibrinogen and fibronectin fragments. Fragment $\mathrm{X}$ of fibrinogen was obtained by limited proteolysis of the purified native protein with plasmin for $2 \mathrm{~h}$ at $37^{\circ} \mathrm{C}$. Fragment $\mathrm{X}$ was purified from the digestion mixture containing still intact fibrinogen, fragments $X$ and $Y$, and some fragment $D$ by gel filtration on Sephacryl S-300 (Pharmacia, Uppsala, Sweden) until the purity was $>90 \%$, as verified by SDS-PAGE [24] and showing a protein of $250-270 \mathrm{kDa}$.

Fibrinogen was more extensively hydrolyzed by plasmin to the major fragments $\mathrm{D}$ and $\mathrm{E}$ in the presence of $1 \mathrm{mM} \mathrm{Ca}{ }^{2+}$ for $16 \mathrm{~h}$ at $37^{\circ} \mathrm{C}$. Fragment $\mathrm{D}$ was isolated from this lysate by affinity chromatography on Gly-Pro-Arg-Pro-Lys-Fractogel as described previously [25]. The purity of fragment $D$ was $>95 \%$ as verified by SDS-PAGE [24], and fragment D was identified as fragment $D_{1}$ with a molecular mass of $90 \mathrm{kDa}$. Fragment $\mathrm{D}_{3}$ was prepared from pure fragment $D_{1}$ by proteolysis with plasmin for $16 \mathrm{~h}$ at $37^{\circ} \mathrm{C}$ in the absence of $\mathrm{Ca}^{2+}$ (achieved by the addition of EDTA, final concentration $2 \mathrm{~m} M$ ). Digestion to fragment $\mathrm{D}_{3}$ was checked by SDS-PAGE (unreduced and reduced [24]). Fragment $\mathrm{D}_{3}$ had a molecular mass of $75 \mathrm{kDa}$ and showed a typical pattern in the reduced gels.

A mixture of two high-molecular-mass tryptic fragments of fibronectin, lacking the $27-\mathrm{kDa}$ amino terminal end containing a $S$. aureus-binding domain $[15,26]$ and previously referred to as the $180-\mathrm{kDa}$ carboxy-terminal fragment [15], was prepared by trypsin digestion as previously described in detail [15]. These fragments, appearing as two closely spaced bands on SDSPAGE (190 and $200 \mathrm{kDa}$ ), have subsequently been shown to be produced from the $A$ and $B$ chains, respectively [27], and to contain the collagen, heparin, and cell-binding regions, but not the carboxy-terminal end including the disulfide bonds connecting both subunits of fibronectin $[27,28]$. The mixture of 190 and $200-\mathrm{kDa}$ fragments was purified from the $27-\mathrm{kDa}$ fragment by chromatography on DEAE-Sepharose. Further purification and characterization of the $190-$ and $200-\mathrm{kDa}$ fragments was done by affinity chromatography on gelatin-Sepharose and SDSPAGE [24], respectively.

Preparation of anti-fibroneciin antibodies. Rabbit antibodies to human fibronectin were prepared as previously described [29, 30]. Briefly, antisera from immunized rabbits were adsorbed onto insolubilized fibronectin-free plasma proteins, and immunoglobulins $\mathrm{G}$ were purified by affinity chromatography on protein A-Sepharose (Pharmacia). A portion of the rabbit immunoglobulins was also selectively depleted of antifibronectin activity by affinity chromatography on fibronectin-Sepharose [31]. This latter preparation was used to evaluate the nonspecific binding of antifibronectin-unrelated $\operatorname{IgG}$ by the in vivo protein-coated catheters.

Labeling of immunoglobulins, fibronectin, fibrinogen, or fragments. Antifibronectin-containing or -depleted preparations of $\mathrm{IgG}$, native fibronectin or fibrinogen, fragments $X$ and $\mathrm{D}_{3}$ of fibrinogen, and the mixture of 190- and 200-kDa tryptic fragments of fibronectin were radiolabeled with ${ }^{3} \mathrm{H}$ by reductive methylation as previously described [32]. The specific activity of the various radiolabeled proteins ranged from 1.0 to $2.5 \times 10^{5}$ $\mathrm{cpm} / \mu \mathrm{g}$ protein.

Quantification of surface-bound fibronectin or fibrinogen. Immunologic and functional assays of surface-bound fibronectin were run with a single type of standard curve, which was generated by in vitro adsorption of the purified protein on $1-\mathrm{cm}-$ long segments of uninserted cannulas. Uninserted cannulas had to be precoated with gelatin to optimize adsorption from protein concentrations $<1 \mathrm{mg} / \mathrm{mL}$. Gelatin precoating was done by incubating each cannula segment at $20^{\circ} \mathrm{C}$ for $1 \mathrm{~h}$ in a $1-\mathrm{mL}$ purified gelatin (Difco, Detroit) solution (1 mg/mL) in PBS (using sterile polystyrene tubes).

After cannulas were rinsed in PBS, standard amounts of fibronectin were adsorbed by incubating at $37^{\circ} \mathrm{C}$ for $1 \mathrm{~h}$ duplicate segments of gelatin-precoated cannulas with protein concentrations ranging from 4.0 to $0.125 \mu \mathrm{g} / \mathrm{mL}$ of PBS. Similar incubating conditions were used to coat native cannulas with standard amounts of fibrinogen, either with protein concentrations ranging from 4.0 to $0.125 \mu \mathrm{g} / \mathrm{mL}$ or at higher concentrations $(8,100$, and $1000 \mu \mathrm{g} / \mathrm{mL}$ ). The amount of surface-bound fibronectin or fibrinogen on the cannula segments was estimated by incubating the cannula segments with the preindicated concentrations of either radiolabeled protein. At the end of the adsorption period, each cannula segment was first rinsed twice in PBS, then immersed in $5 \mathrm{~mL}$ of an emulsion system (Hionic-Fluor; Packard, Zurich) selected for scintillation counting. The standard 
amounts of either fibronectin or fibrinogen adsorbed on each segment were estimated by multiplying counts per minute (cpm) values of cannula-adsorbed radioactivity by the nanogram-to-cpm ratio of the proteins in solution. By using these experimental conditions, the quantity of surface-bound fibronectin and fibrinogen on each cannula segment increased linearly in the range of protein concentration from 0.125 to $1.0 \mu \mathrm{g} / \mathrm{mL}$. Under these conditions, the proportion of protein adsorbed on the cannula segments averaged $10 \%$ and $7 \%$ for fibronectin and fibrinogen, respectively, of the quantity initially added in solution (not shown). Identical procedures of protein adsorption and quantification were used, when fragments of either fibronectin or fibrinogen, prepared and radiolabeled as described above, were adsorbed on segments of uninserted cannulas.

Adherence-promoting activity of in vitro or in vivo cannula-adsorbed proteins. One-centimeter-long segments of either uninserted cannulas coated in vitro with standard amounts of purified proteins or of cannulas removed from patients were incubated at $37^{\circ} \mathrm{C}$ for $1 \mathrm{~h}$ in a previously described $[11,31,33]$ bacterial adherence assay. Briefly, cannula segments were incubated with a constant inoculum of $4 \times 10^{6} \mathrm{cfu}$ of a freshly washed culture of $S$. aureus, metabolically radiolabeled with $\left[{ }^{3} \mathrm{H}\right]$ thymidine in Mueller-Hinton broth $[31,33]$. The isolates of $S$. aureus tested for adherence were either 6 bacteremic isolates collected from iv device infections in a previous study [8] or a single laboratory strain (Cowan I) previously shown to have high affinity to surface-bound fibronectin and fibrinogen [11].

Each cannula segment was incubated with the bacterial suspension for $60 \mathrm{~min}$ in the attachment medium [3], 33] ( $1 \mathrm{~mL}$ of PBS supplemented with $5 \mathrm{mg} / \mathrm{mL}$ purified human albumin [PBSA]) to minimize nonspecific attachment [11] to cannula areas that might be unexposed to plasma proteins (e.g., the lumen). Thereafter, cannula segments were carefully rinsed [11, 31,33 ], and the number of staphylococci specifically bound either to in vitro protein-coated or to inserted cannula segments was estimated by counting radioactivity in a liquid scintillation counter and by multiplying radioactive counts by the colonyforming units-to-cpm ratio of the radiolabeled culture [11, 31, 33].

Immunologic assay of cannula-adsorbed fibronectin. Segments ( $1 \mathrm{~cm}$ long) of cannulas, whether coated with standard amounts of fibronectin as described above or removed from patients, were incubated at $37^{\circ} \mathrm{C}$ for $1 \mathrm{~h}$ with a $1-\mathrm{mL}$ solution containing $10 \mu \mathrm{g}$ of a mixture of radiolabeled $\left(10^{5} \mathrm{cpm}\right)$ and unlabeled IgG, in PBSA supplemented with $0.1 \%$ Tween 20 (PBSAT). Duplicate segments were incubated in parallel with either antifibronectin-containing or-depleted IgG. At the end of the binding period, cannula segments were rinsed twice in PBSAT and counted in a liquid scintillation counter for evaluating IgG-bound radioactivity. The quantity of $\lg G$ bound to each cannula segment was obtained by multiplying each $\mathrm{cpm}$ value by the nanograms of IgG-to-cpm ratio of the incubating solution. The amount of specifically bound antifibronectin IgG antibodies represented the quantity in excess of the background levels of IgG bound by cannula segments incubated with antifibronectin-depleted IgG. The amount of immunoreactive fibronectin on inserted cannulas was estimated by comparing the quantity of antifibronectin antibodies bound by these cath- eters with antibody binding by standard amounts of surfacebound fibronectin, adsorbed in vitro on gelatin-precoated cannula segments as described above.

Radioimmunoassay of cannula-adsorbed fibrin(ogen). The procedure for estimating the total amount of fibrinogen or fibrin deposited on inserted cannulas has been previously described in detail $[11,34]$. After extensive digestion by plasmin of $1-\mathrm{cm}$ long sections of cannulas, the protein digests were assayed for the amount of the late soluble fragment $E$, which remains stable under these conditions [34]. From the amount of fragment E, estimated by RIA using a specific antiserum [34], the quantity of cannula-associated fibrin(ogen) was calculated on the basis of a molecular weight ratio of 48,500 for fragment $E$ to 340,000 for native fibrinogen.

Proteolytic digestion of cannula-adsorbed fibrinogen or fibronectin by plasmin. One-centimeter-long segments of native PUR-V cannulas were coated in vitro with either fibrinogen or fibronectin, $130 \mathrm{ng} / \mathrm{cm}$, by a $60-\mathrm{min}$ incubation at $37^{\circ} \mathrm{C}$ in PBS solutions of either $2 \mu \mathrm{g} / \mathrm{mL}$ fibrinogen or fibronectin. An additional group of uninserted but gelatin-precoated cannulas was coated in vitro with $50 \mathrm{ng} / \mathrm{cm}$ fibronectin in a PBS solution of $0.5 \mu \mathrm{g} / \mathrm{mL}$. After rinsing in PBS, the protein-coated cannula segments were exposed at $37^{\circ} \mathrm{C}$ to $1 \mu \mathrm{g} / \mathrm{mL}$ plasminogen activated to plasmin by 800 units $/ \mathrm{mL}$ urokinase (Choay, Paris) in PBS supplemented with $1 \mathrm{~m} M \mathrm{Ca}^{2+}$ and $0.5 \mathrm{~m} M \mathrm{Mg}^{2+}$. After either 10 or $60 \mathrm{~min}$, the digestion was terminated by adding 10 $\mu \mathrm{L}$ of $10^{-2} M$ D-phenyl-prolyl-arginyl-chloromethyl ketone (PPACK; Bachem, Bubendorf, Switzerland) solution as previously described [25]. Zero time digestion controls were cannula segments incubated for 60 min with PPACK-inactivated plasminogen-urokinase mixture. Control or plasmin-digested cannula segments were then rinsed for $5 \mathrm{~min}$ in PBS and tested for residual adherence-promoting activity with $S$. aureus Cowan as a test strain.

Statistical evaluation of data. Correlation of bacterial adherence-promoting activity with the content of immunologically assayed fibronectin or fibrin(ogen) on inserted cannulas was expressed by Pearson's product moment coefficient as determined by a statistical computer program (Hewlett-Packard, [model 4I$\mathrm{C}$ computer] Geneva). Intergroup differences in bacterial adherence-promoting activity, fibronectin, or fibrin(ogen) content of each category of inserted cannulas were evaluated by MannWhitney test for unrelated rankable scores. All statistical analyses were two-tailed; a $P$ of .05 was considered statistically significant.

\section{Results}

Adherence of $S$. aureus on in vitro versus in vivo proteincoated cannulas. Adding $25 \mathrm{ng} / \mathrm{cm}$ fibronectin to gelatinprecoated PUR-V cannulas in vitro increased adherence of 6 bacteremic isolates of $S$. aureus that were previously isolated from iv device infections [8] by a factor of 4.8 -fold over gelatin-precoated and 15.0-fold over albumin-precoated cannula segments (figure 1A). For comparison, PUR-V cannulas coated with various amounts of purified fibrinogen (66-610 $\mathrm{ng} / \mathrm{cm}$ ) also promoted adherence of the 6 bacteremic isolates 


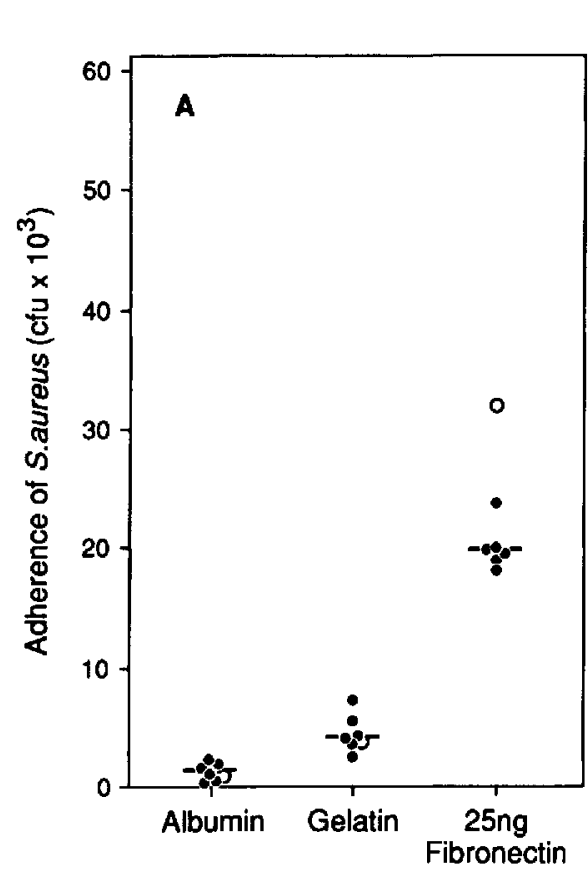

(figure 1B). S. aureus Cowan I, first described as a clinical isolate responsible for hematogenous septic arthritis in humans [35], was promoted by the different proteins deposited on PUR-V cannulas to the same extent as the 6 bacteremic isolates (figure 1). Of note, even dilute solutions of fibrinogen (e.g., $8 \mu \mathrm{g} / \mathrm{mL}$ ), which resulted in a deposition of 403 $\mathrm{ng} / \mathrm{cm}$ (figure 1B), could saturate the system for $S$. aureus adherence. No further increase in $S$. aureus adherence was obtained by coating the cannulas with a 125 -fold higher concentration of fibrinogen that approached its plasma level (figure 1B). Neither soluble fibronectin nor fibrinogen blocked $S$. aureus Cowan I adherence to catheters coated with fibronectin or fibrinogen, respectively (not shown).

Because Cowan I is a stable strain with adherence properties similar to those of the bacteremic isolates of $S$. aureus, we compared its adherence characteristics on in vitro proteincoated cannulas (figure $2 \mathrm{~A}$ ) with those on ex vivo catheters removed from patients (figure $2 B$ ). Eighty catheters were obtained from 80 patients: 65 PUR or PVC cannulas and 15 Hickman catheters. Bacterial adherence studies revealed statistically significant differences between different groups of inserted cannulas (figure 2B), suggesting different contents or activity of adherence-promoting proteins. PUR cannulas of each type promoted a significantly lower adherence of $S$. aureus than PVC $(P<.01$, Mann-Whitney) or Hickman $(P<$ .001 , Mann-Whitney) cannulas. PUR-S cannulas showed even a smaller adherence-promoting activity $(P<.002$, Mann-Whitney) than PUR-V and PUR-C cannulas that showed equivalent results (figure $2 \mathrm{~B}$ ). PUR cannulas were also the only material for which a nonadherence profile was found: $40 \%$ of PUR-V, $90 \%$ of PUR-S, and $55 \%$ of PUR-C cannulas (figure 2B) promoted $S$. aureus adherence less than twofold over gelatin-coated controls and also less than cannulas coated in vitro with only $15 \mathrm{ng} / \mathrm{cm}$ fibrinogen (figure $2 \mathrm{~A})$. In contrast, all inserted PVC $(n=14)$ and Hickman ( $n$ $=15$ ) catheters significantly promoted $S$. aureus Cowan I adherence (by $\geqslant 2.0$ - and 5.5 -fold, respectively) over gelatin controls.

To evaluate the possible influence of plasma protein contamination on these data (figure 2B), we analyzed removed cannulas considered to be contaminated by minute amounts of blood (see Methods) and those considered to be uncontaminated. Separate analysis of the latter subgroup $(n=$ 49) further confirmed that all three categories of inserted PUR cannulas showed an overall smaller adherence-promoting activity than PVC or Hickman cannulas (figure 2B). These findings ruled out that various levels of plasma protein contamination were responsible for the differences in staphylococcal adherence promoted by the different types of inserted cannulas.

Correlation analysis of adherence-promoting activity for inserted catheters with their content of immunologically assayed fibronectin and fibrin(ogen). Further $1-\mathrm{cm}$-long segments of inserted cannulas, adjacent to those assayed for adherencepromoting activity, were compared for the presence of fibronectin or fibrin(ogen). To avoid overestimates of either protein that would result from blood contamination of cannulas, we focused our immunologic assays on cannulas of adequate length that were found to be uncontaminated by peroxidase assay. These were 23 inserted cannulas: 11 PUR, 7 PVC, and 5 Hickman. Overall amounts of fibronectin (figure $3 \mathrm{~A}$ ) differed from those of fibrin(ogen) (figure $3 \mathrm{~B}$ ) by at 
Figure 2. Promotion of $S$. aur eus Cowan I adherence by in vitro coating of native cannulas with purified fibrinogen or fibronectin $(\mathbf{A})$ or by ex vivo protein coating of cannulas previously inserted in 80 patients with 5 different types (B) and either significantly contaminated $(\bullet)$ or uncontaminated $(\mathrm{O})$ with blood. Three brands of polyurethane (PUR-V, PUR-S, PURC) and 1 of polyvinyl chloride (PVC) were used. Duplicate 1-cmlong segments were assayed. Bars, median values for each group.

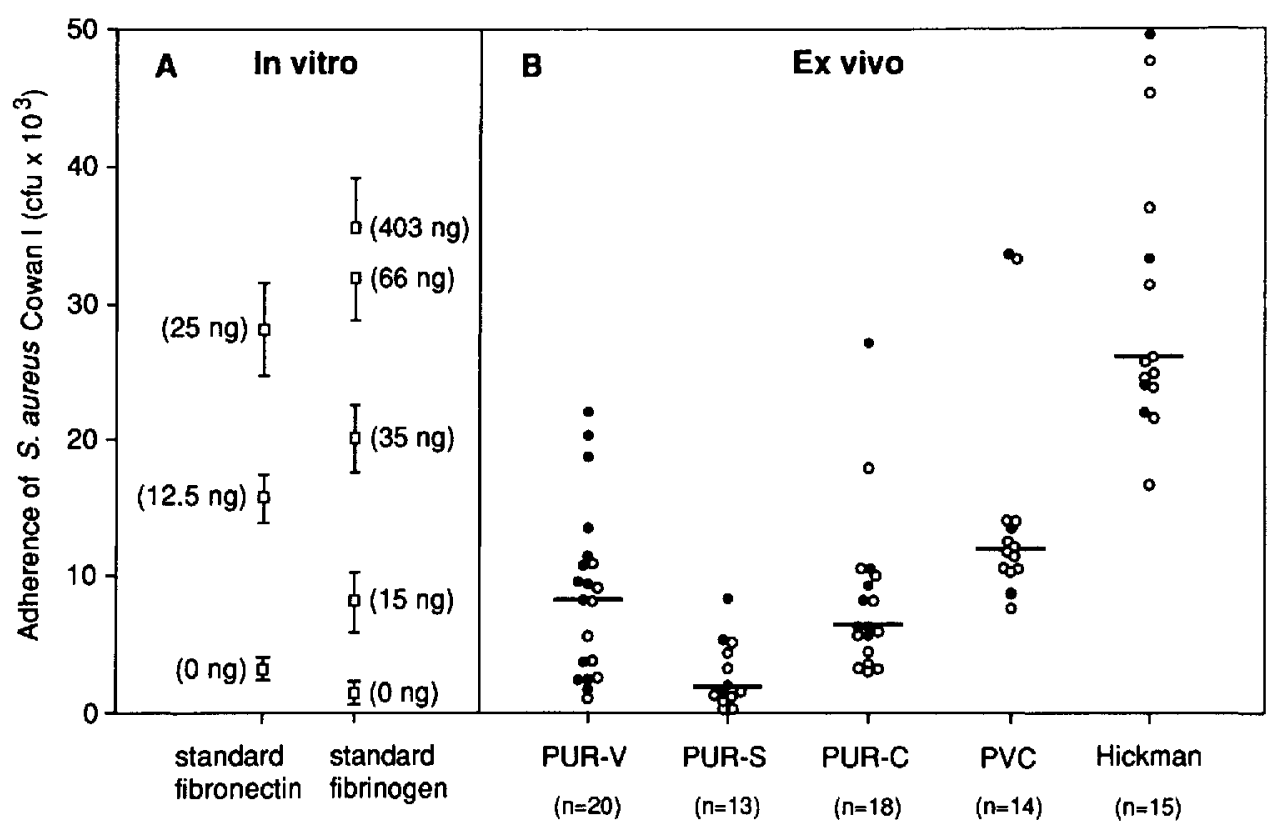

least two orders of magnitude, ranging from 0 to $37 \mathrm{ng} / \mathrm{cm}$ for fibronectin and from $290 \mathrm{ng}$ to $5.64 \mu \mathrm{g} / \mathrm{cm}$ for fibrin(ogen). Each category of inserted catheters yielded a significantly different content of immunologically assayed fibronectin (figure $3 \mathrm{~A}$ ). Median values of fibronectin were 2 $\mathrm{ng} / \mathrm{cm}$ (range, $0-13$ ) for PUR versus $8.3 \mathrm{ng} / \mathrm{cm}$ (range, $5-14 ; P<.05$, Mann-Whitney) for PVC versus $19.5 \mathrm{ng} / \mathrm{cm}$ (range, 11.2-37.0; $P<.002$, Mann-Whitney) for Hickman cannulas. The adherence-promoting activity of each group of inserted cannulas shown in figure $3 \mathrm{~A}$ paralleled their fibronectin content, each group being significantly different from other groups $(P<.002$ for Hickman and PVC vs. PUR cannulas; $P<.02$ for Hickman vs. PVC cannulas; MannWhitney).

No significant differences $(P>.05$, Mann-Whitney) were observed in the median fibrin(ogen) content of either PUR $(0.47 \mu \mathrm{g} / \mathrm{cm})$, PVC $(0.38 \mu \mathrm{g} / \mathrm{cm})$, or Hickman cannulas $(1.02 \mu \mathrm{g} / \mathrm{cm})$. When all cannulas assessed for their protein contents were pooled ( $n=23)$, the extent of $S$. aureus adherence promoted by inserted cannulas was significantly correlated (Pearson's $r=.66, P<.002$ ) with their content of immunologically assayed fibronectin (figure $3 \mathrm{~A}$ ) but not $(r=$ $.14, P>.1$ ) fibrin(ogen) (figure 3B).

Selective inactivation of adherence-promoting activity of $f$ brin(ogen) over fibronectin adsorbed on inserted cannulas. The apparent lack of correlation between the fibrin(ogen) content of inserted cannulas and their adherence-promoting activity might not be a sufficient argument to exclude the contribution of fibrin(ogen) to $S$. aureus adherence. Saturating amounts of this protein may prevent observation of any further dose-dependent promotion of bacterial adherence. We compared S. aureus Cowan I adherence-promoting activity of each group of previously inserted catheters with that of the same materials in vitro coated with native fibrinogen (figures $2 \mathrm{~B}, 3)$. The residual bacterial adherence promoted by the fibrin(ogen) layer recovered on inserted cannulas was
Figure 3. Correlation between adherence-promoting activity of 23 inserted polyurethane (PUR), polyvinyl chloride (PVC), or Hickman cannulas that had either immunologically estimated fibronectin (A) or fibrin(ogen) (B). Indicated correlations were assessed with Pearson's $r$ product moment correlation coefficient.

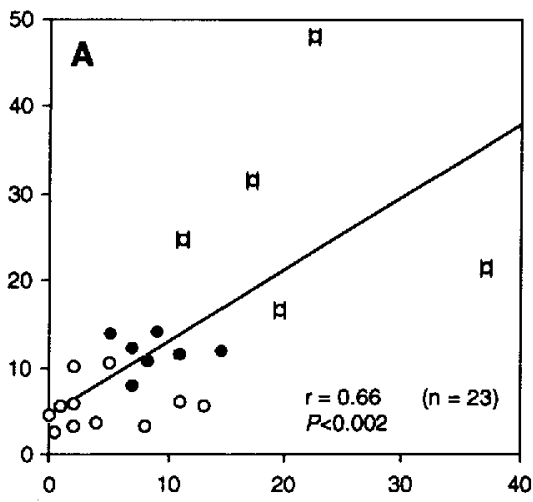

Fibronectin amount $(\mathrm{ng} / \mathrm{cm})$ by immunoassay

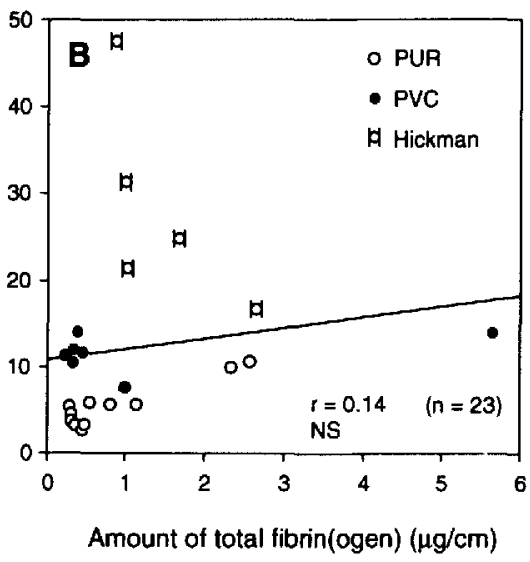


indeed much lower than that promoted by equivalent amounts of native fibrinogen in vitro coating the same materials. The extent of bacterial adherence promoted by ex vivo fibrin(ogen) for each group of inserted cannulas (figure 3A) represented the activity of very low amounts of in vitroadded fibrinogen, namely $6-26 \mathrm{ng} / \mathrm{cm}$ (median, 8 ) for PUR, $15-26 \mathrm{ng} / \mathrm{cm}$ (median, 23) for PVC, and 31-70 $\mathrm{ng} / \mathrm{cm}$ (median, 45) for Hickman cannulas. These median values of functionally active adherence-promoting fibrinogen, as estimated for each group of inserted cannulas, indicated an extensive loss of activity for ex vivo fibrin(ogen), reaching $98 \%$, 94\%, and 96\% for PUR, PVC, and Hickman cannulas, respectively.

In contrast to fibrin(ogen), we found no discrepancy between the quantities of immunologically assayed fibronectin and their adherence-promoting activity on inserted cannulas. The quantities of fibronectin on ex vivo catheters were adequate to promote $S$. aureus Cowan I adherence in the absence of any other major attachment protein. The median quantities of in vitro-added fibronectin (figure $2 \mathrm{~A}$ ) that promoted bacterial adherence to the same extent as inserted cannulas (figure $3 \mathrm{~A}$ ) were estimated to be 2.2 versus $2 \mathrm{ng} / \mathrm{cm}$ for PUR, 9 versus $8.3 \mathrm{ng} / \mathrm{cm}$ for PVC, and 22.2 versus 19.5 $\mathrm{ng} / \mathrm{cm}$ for Hickman cannulas. Thus, amounts of fibronectin recovered from previously inserted PUR, PVC, or Hickman cannulas were equivalent to those determined to signifcantly promote $S$. aureus adherence once coated in vitro onto each type of catheter.

To further analyze the selective inactivation of fibrin(ogen) over fibronectin on inserted catheters, we performed SDS-PAGE and made immunoblots of cannula-associated proteins extracted in SDS-Laemmli buffer [24]. SDS-PAGE showed a very selective deposition on the catheter surface of fibrinogen and fibrin, followed by smaller amounts of plasminogen and fibronectin, respectively. Immunoblots of the proteins separated by SDS-PAGE (data not shown) confirmed the identification of fibrinogen, fibrin, plasminogen, and fibronectin as major components of cannula-extracted proteins. This indicated a selective protein adsorption process from plasma to inserted cannulas, as further supported by the absence of albumin or any other major proteins in silver-stained SDS-PAGE of cannula protein extracts [36]. Immunoblots also revealed the presence of proteolytic fragments of fibrinogen, fibrin, and fibronectin in cannula-extracted proteins.

Effect of proteolytic digestion on adherence-promoting activity of fibrinogen or fibronectin. Proteolytic fragments of fibrinogen and fibronectin were produced either by standard techniques in the liquid phase or by in situ digestion of the native proteins already adsorbed on cannula segments. Figure 4 shows results of studies done for convenience with a single type of cannula (PUR-V) coated with standard fragments of either fibrinogen or fibronectin that were produced in the liquid phase and then adsorbed on cannula segments.

Comparative adherence-promoting activities of native fi- brinogen with its plasmin fragments $[19,20,37-40]$ showed a significant loss of activity for the latter fragments (figure 4A). Whereas optimal promotion of S. aureus Cowan I adherence was achieved with $60 \mathrm{ng}$ of native fibrinogen per $1-\mathrm{cm}$ segment of PUR-V cannula, a fivefold greater amount of fragment $X[37-40]$, which is the first by-product of plasmindigested fibrinogen (removing essentially the carboxy-terminal part of the $\alpha$ chain), was required to obtain a similar activity. More extensive cleavages at concordant locations in the $\alpha, \beta$, and $\gamma$ chains of fibrinogen, which led to separation of their $\mathrm{D}$ and $\mathrm{E}$ domains $[19,20,37-40]$, resulted in an extensive loss of adherence-promoting activity. Whereas the large (early) $D_{1}$ fragment containing a staphylococcal clumping domain $[19,20]$ still slightly promoted $S$. aureus adherence at $300 \mathrm{ng} / 1-\mathrm{cm}$ segment, the smaller (late) $D_{3}$ fragment devoid of staphylococcal clumping domain $[19,20]$ demonstrated complete loss of adherence-promoting activity (figure 4A). Other cannula types (PUR-S, PUR-C, PVC) coated with high amounts of fibrinogen fragment $D_{1}$ or $D_{3}(>300$ $\mathrm{ng} / 1-\mathrm{cm}$ segment) also showed a greatly reduced adherencepromoting activity for $S$. aureus Cowan I, when compared to native fibrinogen (data not shown). Finally, each of the 6 bacteremic isolates of $S$. aureus showed an extensive loss of adherence-promoting activity, similar to that of strain Cowan I, when tested on PUR-V cannulas coated with fragment $D_{1}$ versus native fibrinogen.

In contrast to fibrinogen, fragmented fibronectin could still adequately promote $S$. aureus Cowan I adherence [16, 41]. Previous reports confirmed that the amino-terminal $27-$ kDa tryptic fragment bound specifically to $S$. aureus in suspension [ 15$]$ or after adsorption on surfaces $[16,41]$. We also found a significant adherence-promoting activity in a mixture of 190- and 200-kDa tryptic fragments lacking both the amino- and carboxy-terminal ends of fibronectin [27, 28]. The mixture of $190-$ and $200-\mathrm{kDa}$ fragments adsorbed on gelatin-precoated cannula segments in parallel with intact fibronectin promoted $S$. aureus Cowan I adherence at equivalent amounts of adsorbed protein, although to a slightly lower extent (figure 4B). Similar data (not shown) were obtained with each of the 6 bacteremic isolates of $S$. aureus; all showed the presence of an additional $S$. aureus-binding domain outside the amino-terminal end of fibronectin.

To further confirm the higher susceptibility to proteolytic digestion of surface-bound fibrinogen versus fibronectin, we tested the residual adherence-promoting activity of each protein adsorbed in vitro on PUR-V cannula segments before plasmin digestion. Surface-bound fibrinogen $(130 \mathrm{ng} / \mathrm{cm})$ lost its adherence-promoting activity more rapidly and more extensively than surface-bound fibronectin exposed to plasmin digestion (figure 5). After 10 and $60 \mathrm{~min}$, plasmintreated cannula-bound fibrinogen still expressed only $30 \%$ and $<4 \%$ of residual adherence-promoting activity, respectively. In contrast, similarly treated plasmin-treated cannula segments, whether coated with 120 or $50 \mathrm{ng} / \mathrm{cm}$ fibronectin on native or gelatin-precoated cannulas, respectively, 
Figure 4. Adherence-promoting activity of selected fragments of either fibrinogen (A) or fibronectin (B) on S. aureus Cowan 1. A, Either native fibrinogen or a purified fragment was adsorbed in vitro on uninserted $1-\mathrm{cm}$-long segments of polyurethane (PUR) cannulas from concentrations ranging from $125 \mathrm{ng}$ to $8 \mu \mathrm{g} / \mathrm{mL}$. B, Similar amounts of native fibronectin or of its 190- and 200-kDa tryptic fragments were adsorbed in vitro on gelatin-coated PUR cannulas from concentrations of $125 \mathrm{ng} / \mathrm{mL}$ to 2 $\mu \mathrm{g} / \mathrm{mL}$. Results are means of $2 \mathrm{ex}-$ periments done in duplicate.

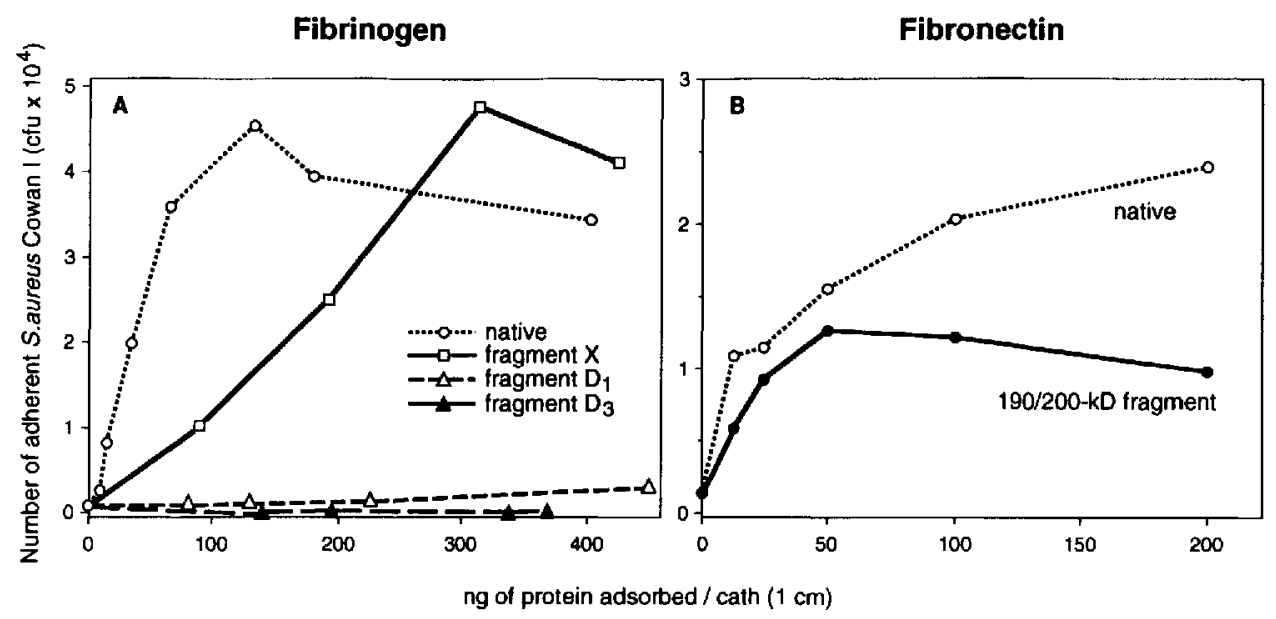

showed a significantly higher $(P<.05$, paired $t$ test $)$ residual adherence-promoting activity, averaging $73 \%$ and $88 \%$ at 10 $\mathrm{min}$ and $34 \%$ and $27 \%$ at $60 \mathrm{~min}$, respectively, of zero time digestion controls (figure 5).

\section{Discussion}

Previously, we demonstrated that most of the functional adherence-promoting activity of inserted catheters was due

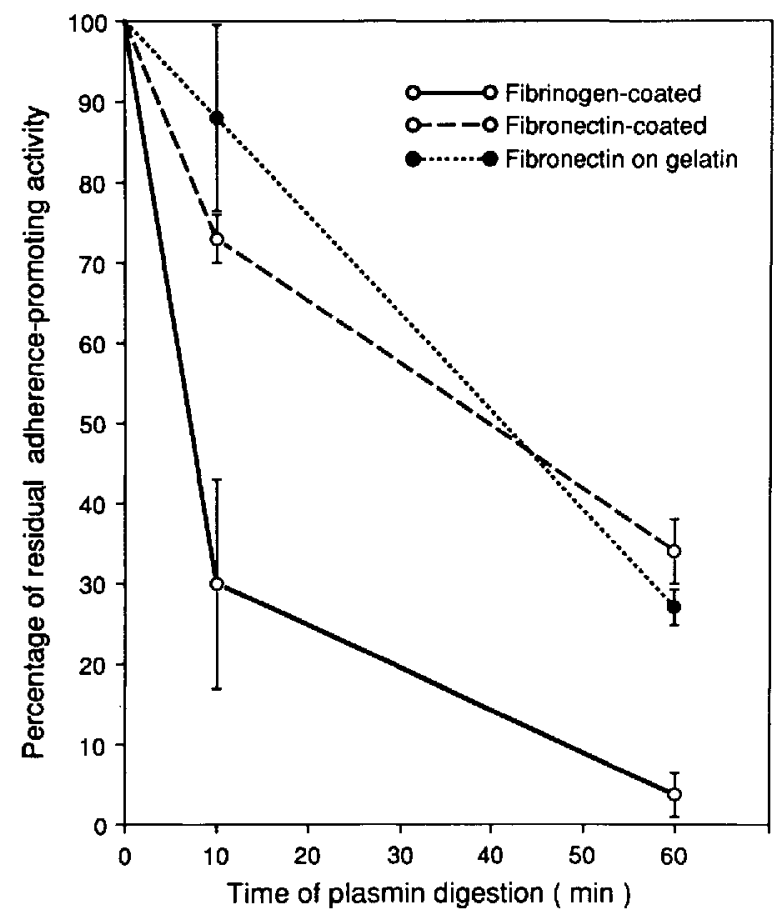

Figure 5. Differential loss of adherence-promoting activity for cannula-adsorbed fibrinogen or fibronectin exposed to plasmin. Residual $S$. aureus Cowan I adherence-promoting activity of fibrinogen, adsorbed at $130 \mathrm{ng} / \mathrm{cm}$, is compared to that of fibronectin, adsorbed at either $120 \mathrm{ng} / \mathrm{cm}$ on native or $50 \mathrm{ng} / \mathrm{cm}$ on gelatin-precoated polyurethane cannulas, after various times of plasmin digestion. Results are means of 3 experiments $\pm S E$. to fibrin(ogen), fibronectin, or both. The present study allows definition of their respective contributions more accurately. While catheters removed from patients contained small amounts of fibronectin, this amount was sufficient to promote a dose-dependent adherence of all clinical strains of $S$. aureus that were tested. Although immunologically reactive fibrin(ogen) was found at higher amounts on cannulas than was fibronectin, it lacked adherence-promoting activity for $S$. aureus. The results clearly indicate that fibrin(ogen) is selectively more inactivated than fibronectin on chronically inserted cannulas. This selective inactivation process was documented by bacterial adherence assays showing a selective loss of adherence-promoting activity for fibrin(ogen) over fibronectin due to plasmin digestion.

$S$. aureus Cowan I was selected as a test organism to probe for the presence of low levels of fibrin(ogen) and fibronectin on the surface of inserted cannulas. This strain was shown to have several characteristics typical of clinical isolates of foreign body infections, namely a high affinity to native fibrinogen and fibronectin and a selective affinity for fragmented fibronectin but not fibrinogen. Although we cannot exclude that other plasma proteins, such as collagen $[13,17]$, laminin $[8,17,22]$, vitronectin $[23,42]$, or thrombospondin [43], might have been present in trace amounts on cannula protein extracts analyzed by SDS-PAGE, further studies are needed to evaluate their possible contribution to $S$. aureus attachment to intravascular devices.

Several lines of evidence suggest that proteolysis of fibrinogen tends to decrease $S$. aureus adherence. Two previous studies $[44,45]$ show that fibrinogen is more susceptible to proteolytic breakdown after adsorption on artificial surfaces than in the liquid phase. Surface-adsorbed fibrinogen could be degraded by activation of trace amounts of surface-adsorbed plasminogen $[44,45]$. Our in vitro studies with purified fibrinogen fragments showed that limited fibrinogen degradation resulted in decreased $S$. aureus binding. In support of our data are studies showing that a substantial proportion of $S$. aureus adherence-promoting activity is lost by a limited plasmin digestion of fibrinogen leading to fragment $X$ and 
thus before removal of the staphylococcal clumping domain $[19,20]$. Further plasmin degradation leads to extensive loss of adherence-promoting activity. Our data suggest that the previously described model for staphylococcal clumping by fibrinogen $[19,20]$ does not apply to surface-bound fibrinogen because the clumping domain is either poorly exposed after adsorption of fibrinogen fragments on PUR cannulas or destroyed by plasmin degradation.

While fibronectin adsorbed on inserted cannulas was presumably also sensitive to plasmin, its adherence-promoting activity seemed to be more resistant to proteolytic degradation than surface-adsorbed fibrin(ogen). Data (shown in figure 5) demonstrated that multiple $S$. aureus-binding regions were still expressed after limited proteolytic attack by different, nonoverlapping fragments of fibronectin. These in vitro data agree with previous observations [16,41] showing the presence of secondary $S$. aureus-binding region(s) of fibronectin, contributing to bacterial adherence, in addition to the initially described $S$. aureus-binding domain located in the $27-\mathrm{kDa}$ amino-terminal segment $[15,16,18,41]$. Whereas we found this secondary binding site in a mixture of 190- and 200-kDa tryptic fragments of fibronectin, which excluded the presence of the amino-terminal domain of the protein, a recent report has localized this site within the heparin-binding domain of fibronectin [46].

Quantitative analysis of cannula-bound fibronectin and fibrin(ogen) by SDS-PAGE and immunoblots was hampered by the presence of nonmigrating proteins, which were presumably factor $\mathrm{XIII}_{\mathrm{a}}$-cross-linked oligomers known to have molecular sizes preventing them from entering SDS-PAGE [37-39]. Despite these limitations, SDS-PAGE and immunoblots still convincingly showed that fibrin(ogen) was the major component of cannula-associated proteins on most clinical specimens analyzed. Fibronectin is also present on the surface of catheters and appears as the predominant $S$. aureus ligand on ex vivo catheters. Of interest, cross-linked fibronectin has been shown in some studies $[12,47]$, but not in others $[9,48]$, to enhance $S$. aureus adherence to thrombi.

In summary, fibronectin has a predominant role over fibrin(ogen) for promotion of $S$. aureus adherence to inserted iv catheters harvested from humans. The role of a selective inactivation process of some cannula-adsorbed proteins, possibly contributing to the lower $S$. aureus adherence-promoting activity of PUR versus PVC or Hickman cannulas remains to be established. We hope that our experimental approach will contribute to an improved molecular understanding of in vivo adherence-promoting activity of biomaterials and to the evaluation of preventive measures that make these materials less susceptible to staphylococcal colonization and infection.

\section{Acknowledgments}

We thank the nurses of Clinique Médicale Thérapeutique and B. Chappuis, I. Bruchweiler, and C. Helg, Oncology Unit, for help in collecting central and Hickman catheters, and E. Frei for excellent technical assistance.

\section{References}

1. Maki DG. Epidemic nosocomial bacteremias. In: Wenzel RP, ed. Handbook of hospital acquired infections. Boca Raton, FL: CRC Press, 1982:371-512.

2. Maki DG. Infections associated with intravascular lines. In: Remington JS, Swartz MN, cds. Current clinical topics in infectious diseases. Vol 3. New York: McGraw-Hill, 1982:309-63.

3. Tenney JH, Moody MR, Newman KA, et al. Adherent microorganisms on lumenal surfaces of long-term intravenous catheters. Arch Intern Med 1986;146:1949-54.

4. Ishak MA, Gröschel DMH, Mandell GL, Wenzel RP. Association of slime with pathogenicity of coagulase-negative staphylococci causing nosocomial septicemia. J Clin Microbiol 1985;22:1025-9.

5. Christensen GD, Baddour LM, Hasty DL, Lowrance JH, Simpson WA. Microbial and foreign body factors in the pathogenesis of medical device infections. In: Bisno AL, Waldvogel FA, eds. Infections associated with indwelling medical devices. Washington, DC: American Society for Microbiology, 1989:27-59.

6. Peters G, Gray ED, Johnson GM. Immunomodulating properties of extracellular slime substance. In: Bisno AL, Waldvogel FA, eds. Infections associated with indwelling medical devices. Washington, DC: American Society for Microbiology, 1989:61-74.

7. Hoshal VL, Ause RG, Hoskins PA. Fibrin sleeve formation on indwelling subclavian central venous catheters. Arch Surg 1971;102:353-8.

8. Hermann M, Vaudaux P, Pittet D, et al. Fibronectin, fibringen, and laminin act as mediators of adherence of clinical staphylococcal isolates to foreign material. J Infect Dis 1988;159:693-701.

9. Cheung AL, Fischetti VA. The role of fibrinogen in staphylococcal adherence to catheters in vitro. $J$ Infect Dis 1990;161:1177-86.

10. Vaudaux P, Lew DP, Waldvogel FA. Host factors predisposing to foreign body infections. In: Bisno AL. Waldvogel FA, eds. Infections associated with indwelling medical devices. Washington, DC: Ameri* can Society for Microbiology, 1989:3-26.

11. Vaudaux P, Pittet D, Haeberli A. et al. Host factors selectively increase staphylococcal adherence on inserted catheters: a role for fibronectin and fibrinogen or fibrin. J Infect Dis 1989;160:865-75.

12. Toy PTCY, Lai L, Drake TA, Sande MA. Effect of fibronectin on adherence of Staphylococcus aureus to fibrin thrombi in vitro. Infect Immun 1985:48:83-6.

13. Holderbaum D, Spech T, Ehrhart LA, Keys T, Hall GS. Collagen binding in clinical isolates of Staphylococcus aureus. J Clin Microbiol 1987;25:2258-61

14. Kuusela P. Fibronectin binds to Staphylococcus aureus. Nature 1978;276:718-20.

15. Mosher DF, Proctor RA. Binding and factor XIIIa-mediated cross-linking of a 27-kilodalton fragment of fibronectin to Slaphylococcus aureus. Science 1980;209:927-9.

16. Kuusela P, Vartio T, Vuento M, Myhre EB. Attachment of staphylococci and streptococci on fibronectin, fibronectin fragments and fibrinogen bound to a solid phase. Infect Immun 1985;50:77-81.

17. Vercellotti GM, McCarthy JB, Lindhom P, Peterson PK. Jacob HS, Furcht LT. Extracellular matrix proteins (fibronectin, laminin, and type IV collagen) bind and aggregate bacteria. Am J Pathol 1985;120:13-21.

18. Signäs C, Raucci G, Jönsson K, et al. Nucleotide sequence of the gene for a fibronectin-binding protein from Staphylococcus aureus: use of this peptide sequence in the synthesis of biologically active peptides. Proc Natl Acad Sci USA 1989;86:699-703. 
19. Hawiger J. Timmons S. Strong DD. Cottrell BA, Riley M. Doolittle RF. Identification of a region of human fibrinogen interacting with the staphylococcal clumping factor. Biochemistry 1982;21:1407-13.

20. Strong DD, Laudano AP. Hawiger J, Doolittle RF. Isolation, characterization, and synthesis of peptides from human fibrinogen that block the staphylococcal clumping reaction and construction of a synthetic clumping peptide. Biochemistry 1982:21:1414-20.

21. Boden MK. Flock JI. Fibrinogen-binding protein/clumping făctor from Staph vlococcus aureus. Infect Immun 1989;57:2358-63.

22. Lopes J, dos Reis M. Brentani RR. Presence of laminin receptors in Staphylococcus aureus. Science 1985:229:275-7.

23. Chhatwal GS. Preissner KT, Müller-Berghaus G, Blobel H. Specific binding of the human S protein (vitronectin) to streptococci, Staphylococcus aureus, and Escherichia coli. Infect Immun 1987:55:187883.

24. Laemmli UK. Cleavage of the structural proteins during assembly of the head of the hacteriophage T4. Nature 1970;227:680-5.

25. Kuyas C, Haeberli A, Walder P, Straub PW. Isolation of human fibrinogen and its derivatives by affinity chromatography on Gly-Pro-ArgPro-Lys-Fractogel. Thromb Haemost 1990;63:439-44.

26. Hayashi M, Yamada KM. Domain structure of the carboxy-terminal half of human plasma fibronectin. J Biol Chem 1983;258:3332-40.

27. Donaldson DJ, Mahan JT, Hasty DL, McCarthy IB. Furcht LT. Location of a fibronectin domain involved in newt epidermal cell migration. J Cell Biol 1985;101:73-8.

28. Yamada KM. Fibronectin domains and receptors. In: Mosher DF, ed. Fibronectin, San Diego: Academic Press, 1989:48-121.

29. Zardi L, Siri A, Carnemolla B, Cosulich E, Viale G, Santi L. A simplified procedure for the preparation of antibodics to serum fibronectin. J Immunol Methods 1980;34: 155-65.

30. Morgenthaler JJ, Baillod P. Friedli H. Isolation of fibronectin under mild conditions. Vox Sang 1984;47:41-6.

31. Vaudaux P, Suzuki R, Waldvogel FA, Morgenthaler JJ, Nydegger UE. Foreign body infection: role of fibronectin as a ligand for the adherence of Staphylococcus aureus. J Infect Dis 1984;1 50:546-53.

32. Spycher MO, Nydegger UE. Part of the activating cross-linked immunoglobulin $G$ is internalized by human platelets to sites not accessible for enzymatic digestion. Blood 1986;67:12-8.

33. Vaudaux P, Waldvogel FA, Morgenthaler JJ, Nydegger UE. Adsorption of fibronectin on polymethylmethacrylate and promotion of Staphylococcus aureus adherence. Infect Immun 1984;45:62-73.

34. Haeberli A, Straub PW. Quantitative determination of fibrin and fibrinogen in biological material. J Lab Clin Med 1980;96:258-66.
35. Cowan ST. Staphylococcal infection in rabbits: antibacterial and nonspecific immunity. J Pathol Bacteriol 1939;48:36-45.

36. Merril CR, Goldman D, Sedman SA, Ebert MH. Ultrasensitive stain for proteins in polyacrylamide gels shows regional variation in cerebrospinal fluid proteins. Science 1981;211:1437-8.

37. Kudryk BJ, Grossman ZD, McAfee JG, Rosenbrough SF. Monoclonal antibodies as probes for fibrin(ogen) proteolysis. In: Chatal JF. ed. Monoclonal antibodies in immunoscintigraphy. Boca Raton. FL: CRC Press, 1989:365-98.

38. Francis CW, Marder VJ. A molecular model of plasmic degradation of crosslinked fibrin. Semin Thromb Hemost 1982;8:25-35.

39. Doolittle RF. Fibrinogen and fibrin. Annu Rev Biochem 1984; 53:195-229.

40. Liu CY, Sobel JH, Weitz JI, Kaplan KL, Nossel HL. Immunological identification of the cleavage products from the $A \alpha-$ and $B \beta$-chains in the early stages of plasmin digestion of fibrinogen. Thromb Haemost 1986;56: 100-6.

41. Vaudaux P, Yasuda H, Velazco MI, et al. Role of host and bacterial factors in modulating staphylococcal adhesion to implanted polymer surfaces. J Biomater Appl 1990;5:134-53.

42. Bale MD, Wolfarth LA, Mosher DF, Tomasini B, Sutton RC. Identification of vitronectin as a major plasma protein adsorbed on polymer surfaces of different copolymer composition. Blood 1989;74:2698706.

43. Herrmann M, Suchard SJ, Boxer LA, Waldvogel FA, Lew DP. Thrombospondin binds to Staphylococcus aureus and promotes staphylococcal adherence to surfaces. Infect Immun 1991;59:279-88.

44. Brash JL, Thibodeau JA. Identification of proteins adsorbed from human plasma to glass bead columns: plasmin-induced degradation of adsorbed fibrinogen. J Biomed Mater Res 1986:20:1263-75.

45. Brash JL, Chan MC, Szota P. Thibodeau JA. Degradation of adsorbed fibrinogen by surface-generated plasmin. J Biomed Mater Res 1985; 19:1017-29.

46. Bozzini S, Visai L, Pignatti P, Petersen TE, Speziale P. Multiple binding sites in fibronectin and the staphylococcal fibronectin receptor. Eur J Biochem 1992;207:327-33.

47. Raja RH. Raucci G, Höök M. Peptide analogs to a fibronectin receptor inhibit attachment of Staphylococcus aureus to fibronectin-containing substrates. Infect Immun 1990;58:2593-8.

48. Chhatwal GS, Valentin-Weigand P, Timmis KN. Bacterial infection of wounds: fibronectin-mediated adherence of group $\mathrm{A}$ and $\mathrm{C}$ streptococci to fibrin thrombi in vitro. Infect Immun 1990;58:3015-9. 